\title{
PERENCANAAN JADWAL INDUK PRODUKSI KOMPONEN BAND KOMP BATTERY DI PT. MADA WIKRI TUNGGAL
}

\author{
Aldi Raihan ${ }^{1}$, Dene Herwanto ${ }^{2}$ \\ Program Studi Tenik Industri, Universitas Singaperbangsa Karawang \\ aldi.raihan17027@student.unsika.ac.id ${ }^{1}$, dene.herwanto@ft.unsika.ac.id ${ }^{2}$
}

Submitted January 30, 2021; Revised March 10, 2021; Accepted March 14, 2021

\begin{abstract}
Abstrak
PT. Mada Wikri Tunggal adalah perusahaan yang bergerak dibidang industri otomotif yang memproduksi komponen-komponen kecil pada bagian motor. Masalah umum yang dialami setiap perusahan produksi yaitu terdapat pada perencanaan jumlah produksi yang harus sesuai dengan kapasitas produksi ditambah lagi dengan permintaan yang mengalami fluktuasi. Agar perusahaan dapat membuat pesanan sesuai dengan kapasitas dan juga waktunya diperlukan Jadwal Induk Produksi. Metode yang digunakan yaitu metode tenaga kerja berubah. Karena metode tersebut sangat cocok untuk perusahaan yang mengalami permintaan yang fluktuatif. Hasil yang diperoleh yaitu perusahaan dapat memenuhi permintaan yang ada untuk periode Januari sampai dengan Desember 2021 sebanyak 48507 unit. Ongkos Reguler Time dalam 12 periode/1 tahun yaitu sebesar Rp. 242.685.000. Ongkos Hiring dalam 1 tahun yaitu sebesar Rp. 16.000.000. Ongkos Lay Off dalam 1 tahun yaitu sebesar Rp. 20.000.000. Dan ongkos Under Time selama 1 tahun yaitu sebesar Rp. 1.750.000. Jadi total ongkos produksi PT. Mada Wikri Tunggal sebesar Rp. 280.435.000.
\end{abstract}

Kata Kunci : Jadwal Induk Produksi, Metode tenaga kerja berubah, Total ongkos produksi

\begin{abstract}
PT. Mada Wikri Tunggal is a company engaged in the automotive industry which produces small components in motor parts. A common problem experienced by each production company is the planning for the amount of production that must be in accordance with the production capacity coupled with fluctuating demand. So that companies can make orders according to capacity and also the time required for a Master Production Schedule. The method used is the changing labor method. Because this method is very suitable for companies that experience fluctuating demand. The results obtained are that the company can meet the existing demand for the period January to December 2021 as many as 48507 units. The Regular Time fare in 12 periods / 1 year is Rp. 242,685,000. The Hiring fee in 1 year is Rp. 16,000,000. The Lay Off fee in 1 year is Rp. 20,000,000. And the cost of Under Time for 1 year is Rp. 1,750,000. So the total production cost of PT. Mada Wikri Tunggal of Rp. 280,435,000.
\end{abstract}

Key Words : Master Production Schedule, Change labor method, Total cost of production

\section{PENDAHULUAN}

Pada era globalisasi ini, perusahaan dihadapkan dengan tingkat persaingan antar perusahaan manufaktur yang semakin ketat. Dengan meningkatnya persaingan antar perusahaan, konsumen semakin tidak ingin menunggu lama untuk mendapatkan pesanannya. Oleh karena itu, perusahaan yang mampu menghasilkan produk yang tepat waktu dan tepat jumlah merupakan perusahaan yang mampu bertahan dalam persaingan [1].

Sektor industri manufaktur yang mengalami pertumbuhan cukup baik adalah sektor industri kendaraan bermotor. Salah satu perusahaan industri kendaraan 
bermotor yaitu PT. Mada Wikri Tunggal yang memproduksi komponen-komponen kecil pada kendaraan bermotor. Produk yang digunakan untuk membuat komponen pada kendaraan bermotor yaitu plastik dan metal seperti clamper, stay comp, cover eng, nut clip, cover handle, cover inner, grip comp, cover battery.

Dengan bertambahnya permintaan maka perusahaan dituntut untuk menggunakan strategi agar permintaan konsumen dapat dilakukan. Forecasting atau peramalan adalah salah satu strategi yang biasa digunakan perusahaan untuk memperkirakan permintaan di periode yang akan datang.

Adapun strategi yang dapat digunakan untuk membantu perusahaan dalam melakukan penjadwalan produksi yaitu dengan melakukan penyusunan Master Production Schedule (MPS). Jadwal Induk Produksi (JIP) atau disebut juga Master Production Schedule (MPS) [2].

Adapun tujuan dari rencana produksi adalah [3] :

a. Sebagai langkah awal untuk menentukan aktivitas produksi yaitu sebagai referensi perencanaan lebih rinci dari rencana agregat menjadi item dalam jadwal induk produksi.

b. Sebagai masukan rencana sumber daya sehingga perencanaan sumber daya dapat dikembangkan untuk mendukung perencanaan produksi.

c. Meredam (stabilisasi) produksi dan tenaga kerja terhadap fluktuasi permintaan.

Beberapa perusahaan mempunyai kebijakan sendiri mengenai masalah produksi, berbagai metode digunakan agar perusahaan dapat memenuhi kebutuhan konsumen yaitu metode tenaga kerja tetap dan tenaga kerja berubah. Perusahaan dengan metode tenaga tetap merupakan perusahaan yang membuat produk dengan tenaga kerja yang tetap selama 12 periode atau 1 tahun, sedangkan perusahaan dengan metode tenaga kerja berubah yaitu perusahaan yang membuat produk dengan tenaga kerja yang berbeda jumlah di tiap periode tergantung dari permintaan dan juga jam tersedia man power [4].

Dalam melakukan produksi, perusahaan juga harus memperhatikan kapasitasnya. Kapasitas adalah kemampuan memproduksi secara optimum dari sebuah fasilitas atau bisa disebut sebagai jumlah output pada suatu periode tertentu [5].

Kekurangan kapasitas dapat menyebabkan kegagalan dalam memenuhi target produksi sehingga akan mengakibatkan keterlambatan pengiriman ke konsumen yang dapat menyebabkan perusahaan kehilangan kepercayaan dan juga merusak reputasi perusahaan [6].

Namun pada era pandemic ini menyebabkan terjadinya fluktuasi permintaan pada komponen Band Komp Battery. Dimana fluktuasi sendiri dapat menyebabkan goncangan pada perekonomian maupun bisnis di perusahaan. Dengan demikian perusahaan harus mencari cara bagaimana meramalkan dan merencanakan produksi serta mengantisipasi fluktuasi permintaan pada komponen Band Komp Battery.

Dari pemaparan diatas didapatkan bahwa tujuan dari penelitian ini yaitu untuk mengetahui bagaimana penyusunan Master Production Schedule (MPS) untuk menjadwalkan material yang akan diproduksi menjadi suatu komponen otomotif agar produksi dapat berjalan sesuai dengan permintaan serta mengantisipasi terjadinya fluktuasi pada permintaan komponen Band Komp Battery.

\section{METODE PENELITIAN}

Penelitian ini dilakukan di PT. Mada Wikri Tunggal dengan teknik eksperimen karena ini adalah percobaan menggunakan metode 
tenaga kerja berubah sedangkan pada perusahaan menggunakan metode tenaga kerja tetap. Penelitian ini langsung dilakukan di bagian Production Planning and Inventory Control (PPIC). Dimana objek penelitiannya adalah komponen Band Komp Battery.

MPS menggunakan empat jenis input, yaitu [7] :

a. Data permintaan total, sebagai sumber data bagi proses penjadwalan induk. Data permintaan total berkaitan dengan ramalan penjualan dan pemesanan.

b. Status inventori, berisikan tentang informasi mengenai inventory on hand dan pesanan produksi.

c. Rencana produksi, berisikan tentang inventori awal, kebutuhan produksi, invetori akhir dan lainnya.

d. Data perencanaan, berkaitan dengan aturan-aturan lot sizing, safety stock dan lainnya.

Adapun aktivitas-aktivitas yang dilakukan untuk menyusun MPS mencakup empat fungsi utama yaitu [2] :

a. Menyediakan atau memberikan input utama kepada sistem perencanaan kebutuhan material dan kapasitas (Material and Capacity Requirements Planning $=\mathrm{M} \& \mathrm{CRP}) \quad \mathrm{M} \& \mathrm{CRP}$ merupakan aktivitas perencanaan level 3 dalam hierarki perencanaan prioritas dan perencanaan kapasitas pada sistem MRP II

b. Menjadwalkan pesanan - pesanan produksi dan pembelian (Production and Purchase Orders) untuk item-item MPS.

c. Memberikan landasan untuk kebutuhan sumber daya dan kapasitas.

d. Pemberian basis untuk pembuatan janji tentang penyerahan produk (Delivery Promises) kepada pelanggan.

Alur proses penelitian dimulai dari data urutan proses produksi, data kapasitas ratarata setiap work center, data permintaan produk dari Januari 2020 sampai Desember
2020 untuk meramalkan permintaan produk satu tahun ke depan dengan metode tenaga kerja berubah serta jumlah hari kerja dan jam kerja efektif untuk perhitungan kapasitas yang dibutuhkan dan kapasitas tersedia pabrik. Adapun langkahlangkah untuk menghitung metode tenaga kerja berubah adalah sebagai berikut [8] :

a. Menentukan rencana produksi untuk periode waktu tertentu: Demand Inventory Awal

b. Tentuka kebutuhan jam Man Power untuk periode waktu tertentu

c. Tentukan kebutuhan tenaga kerja untuk periode waktu tertentu

d. Lakukan perencanaan untuk periode waktu tertentu

e. Hitung jumlah unit yang dapat diproduksi pada Reguler Time.

f. Hitung jumlah unit yang terjadi diproduksi Over Time (jika diperlukan). Nilai UPOT ada jika melebihi besarnya kapasitas (tabel kapasitas), maka yang dimasukkan besarnya nilai kapasitas dan untuk sisanya dimasukkan ke sub-kontrak.

g. Jumlah unit yang dapat diproduksi pada sub-kontrak (jika diperlukan) Sub-kontrak ada jika nilai UPOT melebihi nilai kapasitas (yang ada dalam tabel kapasitas), maka sisanya dapat dimasukkan ke sub-kontrak.

h. Hitung Invetory Akhir pada tiap periode/bulan : Inventory Akhir = UPRT - Demand + Inventory Awal

i. Hitung semua ongkos yang terjadi (Total Cost).

\section{HASIL DAN PEMBAHASAN}

Permintaan Band Komp Battery pada bulan Januari sampai Desember 2020 dapat dilihat pada Tabel 1. 
Tabel 1. Tabel Permintaan Band Komp Battery Tahun 2020

\begin{tabular}{ccc}
\hline Periode & Bulan & Permintaan \\
\hline 1. & Januari & 4100 \\
2. & Februari & 4050 \\
3. & Maret & 4200 \\
4. & April & 4200 \\
5. & Mei & 4255 \\
6. & Juni & 4187 \\
7. & Juli & 4070 \\
8. & Agustus & 4165 \\
9. & September & 4100 \\
10. & Oktober & 4032 \\
11. & November & 4065 \\
12. & Desember & 4093 \\
\hline
\end{tabular}

(Sumber : Dokumen PT. Mada Wikri Tunggal, 2020)

Data penunjang yang digunakan untuk membuat Jadwal Induk Produksi, diantaranya sebagai berikut:

$$
\begin{array}{ll}
\text { Jam kerja } & =8 \mathrm{jam} \\
\text { Inventory awal } & =370 \mathrm{unit} \\
\text { Waktu baku } & =72 \text { menit } / 1,2 \mathrm{jam} \\
\text { Safety Stock } & =10 \% \\
\text { Regular Time Cost } & =\mathrm{Rp} .5000,00 / \text { unit } \\
\text { Lay Off Cost } & =\mathrm{Rp} .4 .000 .000,00 / \\
& \text { orang }
\end{array}
$$

$$
\begin{array}{ll}
\text { Hiring Cost } & =\mathrm{Rp} .4 .000 .000,00 / \\
\text { Under Time Cost } & \text { orang } \\
& =\mathrm{Rp} .5 .000,00 / \\
& \text { orang }
\end{array}
$$

Tabel 2. Peramalan Band Komp Battery

\begin{tabular}{ccc}
\hline Periode & Bulan & Peramalan \\
\hline 1. & Januari & 4081 \\
2. & Februari & 4074 \\
3. & Maret & 4067 \\
4. & April & 4060 \\
5. & Mei & 4053 \\
6. & Juni & 4046 \\
7. & Juli & 4039 \\
8. & Agustus & 4032 \\
9. & September & 4025 \\
10. & Oktober & 4018 \\
11. & November & 4011 \\
12. & Desember & 4004 \\
\hline
\end{tabular}

Peramalan pada Tabel $\mathbf{2}$ dihitung menggunakan cara Regresi Linier karena Regresi Linier merupakan metode yang memiliki tingkat MSE (error) yang lebih kecil dibandingkan dengan metode Moving Average. Metode Regresi mampu memberikan perbaikan nilai error dibandingkan metode Moving Average [9]

Tabel 3. Tabel Rencana Produksi

\begin{tabular}{|c|c|c|c|c|c|}
\hline Periode & Inventory Awal & Demand (forecast) & Safety Stock & Kebutuhan Produksi & Inventory Akhir \\
\hline 1 & 370 & 4081 & 408 & 4119 & 408 \\
\hline 2 & 408 & 4074 & 407 & 4073 & 407 \\
\hline 3 & 407 & 4067 & 407 & 4066 & 407 \\
\hline 4 & 407 & 4060 & 406 & 4059 & 406 \\
\hline 5 & 406 & 4053 & 405 & 4052 & 405 \\
\hline 6 & 405 & 4046 & 405 & 4045 & 405 \\
\hline 7 & 405 & 4039 & 404 & 4038 & 404 \\
\hline 8 & 404 & 4032 & 403 & 4031 & 403 \\
\hline 9 & 403 & 4025 & 402 & 4024 & 402 \\
\hline 10 & 402 & 4018 & 402 & 4017 & 402 \\
\hline 11 & 402 & 4011 & 401 & 4010 & 401 \\
\hline 12 & 401 & 4004 & 400 & 4003 & 400 \\
\hline
\end{tabular}

(Sumber : Hasil perhitungan peneliti, 2021)

Pada Tabel 3 merupakan hasil perhitungan rencana produksi dengan menggunakan permintaan yang sudah diramalkan untuk nantinya digunakan sebagai acuan dalam memproduksi komponen Band Komp Battery.
Dalam membuat rencana produksi harus memperhatikan safety stock dan inventori akhir karena dua hal tersebut sangat penting bagi perusahaan untuk menjaga persediaan barang di perusahaan dan menghindari resiko kehabisan bahan dan keterlambatan produksi [10]. 
Tabel 4. Tabel Tenaga Kerja Berubah

\begin{tabular}{|c|c|c|c|c|c|c|c|c|c|c|}
\hline Periode & Demand (Forecast) & HK & TK & Man Power & UPRT & RMHP & RMH & Hiring & Lay Off & Under Time \\
\hline 1 & 4081 & 20 & 31 & 5881 & 4119 & 4943 & 4960 & 0 & 0 & 17 \\
\hline 2 & 4074 & 21 & 29 & 5866 & 4073 & 4888 & 4872 & 0 & 2 & 0 \\
\hline 3 & 4067 & 21 & 29 & 5856 & 4066 & 4879 & 4872 & 0 & 0 & 0 \\
\hline 4 & 4060 & 21 & 29 & 5846 & 4059 & 4871 & 4872 & 0 & 0 & 1 \\
\hline 5 & 4053 & 20 & 30 & 5836 & 4052 & 4863 & 4863 & 1 & 0 & 0 \\
\hline 6 & 4046 & 20 & 30 & 5826 & 4045 & 4854 & 4863 & 0 & 0 & 9 \\
\hline 7 & 4039 & 22 & 28 & 5816 & 4038 & 4846 & 4928 & 0 & 2 & 82 \\
\hline 8 & 4032 & 21 & 29 & 5806 & 4031 & 4837 & 4872 & 1 & 0 & 35 \\
\hline 9 & 4025 & 20 & 30 & 5796 & 4024 & 4829 & 4863 & 1 & 0 & 34 \\
\hline 10 & 4018 & 21 & 29 & 5785 & 4017 & 4820 & 4872 & 0 & 1 & 52 \\
\hline 11 & 4011 & 21 & 29 & 5775 & 4010 & 4812 & 4872 & 0 & 0 & 6 \\
\hline 12 & 4004 & 20 & 30 & 5765 & 4003 & 4804 & 4863 & 1 & 0 & 60 \\
\hline
\end{tabular}

(Sumber : Hasil perhitungan peneliti, 2021)

Pada Tabel 4 berisikan informasi untuk perusahaan mengenai di periode mana saja perusahaan harus menambah atau mengurangi tenaga kerja, dengan demikian perusahaan akan melakukan produksi sesuai dengan permintaan. Adapun contoh beberapa pemaparan metode tenaga kerja berubah sebagai berikut :

\section{Periode 1}

1. UPRT

$=$ Demand + Safety stock - Inventory awal

$=4081+(4081 \times 10 \%)-370=4119$

2. Man Power $=(4119+(10 \% \times 4119)$ $+370) \times 1,2$ jam

Man Power $=5881$ jam

3. Jumlah tenaga kerja

$=\frac{\text { Demand } \mathrm{x} \text { waktu baku }}{\text { Hari kerja } \mathrm{x} \text { jam kerja }}$

$=\frac{4081 \times 1,2}{20 \times 8}$

$=31$ tenaga kerja

4. Regular Man Hour Product=

UPRT x Waktu baku

$$
\begin{aligned}
& =4119 \times 1,2 \\
& =4943 \mathrm{jam}
\end{aligned}
$$

Regular Man Hour $\quad=$ TK $\mathrm{x}$ HK $\mathrm{x}$ JK

$$
\begin{aligned}
& =31 \times 20 \times 8 \\
& =4960 \mathrm{jam} \\
\text { Under Time } & =\mathrm{RMH}-\mathrm{RMHP} \\
& =4960-4943 \\
& =17
\end{aligned}
$$

\section{Periode 2}

1. UPRT

$=$ Demand + Safety stock - Inventory awal

$=4074+(4074 \times 10 \%)-408=$ 4073

2. Man Power $=(4073+(10 \% \times 4073)$ $+408) \times 1,2$ jam

Man Power $=5866$ jam

3. Jumlah tenaga kerja

$$
\begin{aligned}
& =\frac{\text { Demand } \times \text { waktu baku }}{\text { Hari kerja } \times \text { jam kerja }} \\
& =\frac{4073 \times 1,2}{21 \times 8} \\
& =29 \text { tenaga kerja }
\end{aligned}
$$

4. Regular Man Hour Product= UPRT x Waktu baku

$$
\begin{aligned}
& =4073 \times 1,2 \\
& =4888 \mathrm{jam}
\end{aligned}
$$

Regular Man Hour = TK x HK x JK

$$
\begin{aligned}
& =29 \times 21 \times 8 \\
& =4872 \mathrm{jam} \\
& =\mathrm{RMH}-\mathrm{RMHP} \\
& =4872-4888 \\
& =0
\end{aligned}
$$

\section{Periode 3}

1. UPRT

$=4067+(10 \% \times 4067)-407=4066$

2. Man Power $=(4067+(10 \% \times 4067)$

$+407) \times 1,2$ jam

Man Power $=5856$ jam 
STRING (Satuan Tulisan Riset dan Inovasi Teknologi)

Vol. 5 No. 3 April 2021
p-ISSN: 2527 - 9661

e-ISSN: 2549 - 2837

$$
=4879 \text { unit/jam }
$$

Regular Man Hour = TK x HK x JK

Under Time

$$
\begin{aligned}
& =29 \times 21 \times 8 \\
& =4872 \mathrm{jam}
\end{aligned}
$$

$=29$ tenaga kerja

4. Regular Man Hour Product= UPRT x Waktu baku $=4066 \times 1,2$

Tabel 5. Tabel Ongkos Produksi Tenaga Kerja Berubah

\begin{tabular}{|c|c|c|c|c|}
\hline Periode & Ongkos RT & Ongkos Hiring & Ongkos Lay Off & Ongkos Under Time \\
\hline 1 & 20595000 & 0 & 0 & 85000 \\
\hline 2 & 20365000 & 0 & 8000000 & 0 \\
\hline 3 & 20330000 & 0 & 0 & 0 \\
\hline 4 & 20295000 & 0 & 0 & 5000 \\
\hline 5 & 20260000 & 4000000 & 0 & 0 \\
\hline 6 & 20225000 & 0 & 0 & 45000 \\
\hline 7 & 20190000 & 0 & 8000000 & 410000 \\
\hline 8 & 20155000 & 4000000 & 0 & 175000 \\
\hline 9 & 20120000 & 4000000 & 0 & 170000 \\
\hline 10 & 20085000 & 0 & 4000000 & 260000 \\
\hline 11 & 20050000 & 0 & 0 & 300000 \\
\hline 12 & 20015000 & 4000000 & 0 & 300000 \\
\hline Total & 242685000 & 16000000 & 20000000 & 1750000 \\
\hline
\end{tabular}

\section{Periode 1}

Ongkos Regular Time $=$ UPRT x Ongkos RT

$$
\begin{aligned}
& =4119 \times 5000 \\
& =\text { Rp. } 20.595 .000,00
\end{aligned}
$$

Ongkos Hiring $=$ Hiring $\mathrm{x}$ Hiring cost

$$
\begin{aligned}
& =0 \times 4.000 .000 \\
& =0
\end{aligned}
$$

Ongkos Lay Off = Lay Off x Lay Off cost

$$
\begin{aligned}
& =0 \times 4.000 .000 \\
& =0
\end{aligned}
$$

Ongkos Under Time = Under Time $\mathrm{x}$

Under Time cost

$$
\begin{aligned}
& =17 \times 5000 \\
& =85.000
\end{aligned}
$$

\section{Periode 2}

Ongkos Regular Time $=$ UPRT x Ongkos RT

$$
\begin{aligned}
& =4073 \times 5000 \\
& =\text { Rp. } 20.365 .000,00
\end{aligned}
$$

Ongkos Hiring $=$ Hiring $\mathrm{x}$ Hiring cost

$$
\begin{aligned}
& =0 \times 4.000 .000 \\
& =0
\end{aligned}
$$

Ongkos Lay Off = Lay Off x Lay Off cost

$$
\begin{aligned}
& =2 \times 4.000 .000 \\
& =\text { Rp. } 8.000 .000,00
\end{aligned}
$$

Ongkos Under Time = Under Time $\mathrm{x}$

Under Time cost

$$
\begin{aligned}
& =0 \times 5000 \\
& =0
\end{aligned}
$$

\section{Periode 3}

Ongkos Regular Time $=$ UPRT x Ongkos RT

$$
\begin{aligned}
& =4066 \times 5000 \\
& =\text { Rp. } 20.330 .000,00
\end{aligned}
$$

Ongkos Hiring $=$ Hiring $\mathrm{x}$ Hiring cost

$$
\begin{aligned}
& =0 \times 4.000 .000 \\
& =0
\end{aligned}
$$

Ongkos Lay Off = Lay Off x Lay Off cost

$$
\begin{aligned}
& =0 \times 4.000 .000 \\
& =0
\end{aligned}
$$


Ongkos Under Time = Under Time $\mathrm{x}$ Under Time cost

$$
\begin{aligned}
& =0 \times 5000 \\
& =0
\end{aligned}
$$

Total Ongkos Produksi

$=$ Ongkos RT + Ongkos Hiring + Ongkos

Lay Off + Ongkos Under Time

$=242.685 .000+16.000 .000+20.000 .000$

$+1.750 .000$

$=$ Rp. 280.435.000,00

Berdasarkan perhitungan diatas didapatkan bahwa total ongkos Regular Time yaitu waktu yang dibutuhkan untuk melakukan produksi selama 1 periode sesuai dengan jumlah unit yang harus diproduksi pada periode 1 adalah Rp. 20.595.000. Karena tidak ada penambahan dan pengurangan tenaga kerja maka tidak ada ongkos Hiring dan Lay Off. Dan juga untuk ongkos Under Time sebesar 85.000. Sedangkan pada periode 2 memiliki hasil ongkos Regular Time sebesar Rp. 20.365.000. Tidak ada ongkos Hiring dan Under Time, tetapi memiliki ongkos Lay Off sebesar 8.000.000.

Ada beberapa periode yang mengharuskan melakukan penambahan atau pengurangan tenaga kerja, faktor yang paling berpengaruh adalah fluktuasi yang menyebabkan permintaan tidak stabil dan jumlah hari kerja. Jika ada perbedaan yang cukup besar antara permintaan dan jumlah hari kerja kemungkinan akan terjadi penambahan atau pengurangan tenaga kerja.

Hal itu bisa terjadi karena ketika permintaan melonjak tinggi tetapi jumlah hari kerja yang kurang banyak otomatis perusahaan akan membutuhkan tenaga kerja yang banyak. Sedangkan ketika permintaan menurun tetapi jumlah hari kerja cukup banyak maka tidak memerlukan tenaga kerja yang banyak.
Contohnya seperti ketika memiliki permintaan sebesar 4500 dan memiliki jumlah hari kerja 19 hari dalam 1 periode maka perusahaan akan membutuhkan tenaga kerja sebesar 35 sampai 36 tenaga kerja (dengan waktu baku 1,2 jam dan jam kerja 8 jam). Tetapi pada periode selanjutnya permintaan mengalami penurunan menjadi 3900 sedangkan jumlah hari kerja yang cukup banyak yaitu 21 hari, maka perusahaan membutuhkan tenaga kerja sebanyak 27 tenaga kerja saja. Dengan begitu perusahaan harus mengurangi (Lay Off) tenaga kerja sebanyak 8 sampai 9 orang. Pengurangan atau penambahan tenaga kerja ini bergantung pada keadaan saat ini.

\section{SIMPULAN}

Proses perencanaan produksi ini menggunakan metode tenaga kerja berubah yang dilakukan di PT. Mada Wikri Tunggal. Dengan kapasitas Reguler Man Hour (RMH) sebanyak 69854 jam, perusahaan dapat memenuhi permintaan yang ada untuk periode Januari sampai dengan Desember 2021 sebanyak 48507 unit. Ongkos Reguler Time dalam 12 periode/1 tahun yaitu sebesar $\mathrm{Rp}$. 242.685.000. Ongkos Hiring dalam 1 tahun yaitu sebesar Rp. 16.000.000. Ongkos Lay Off dalam 1 tahun yaitu sebesar Rp. 20.000.000. Dan ongkos Under Time selama 1 tahun yaitu sebesar Rp. 1.750.000. Jadi total ongkos produksi PT. Mada Wikri Tunggal sebesar Rp. 280.435.000.

Penggunaan metode tenaga kerja berubah ini dapat digunakan ketika perusahaan sedang mengalami permintaan yang fluktuatif karena dapat mengurangi atau menambahkan tenaga kerja sesuai dengan keadaan permintaan di perusahaan. 


\section{DAFTAR PUSTAKA}

[1] A. Rasbina, S. Sinulingga, and I. Siregar, "Perencanaan Jadwal Induk Produksi Pada PT. XYZ," E-Jurnal Tek. Ind. FT USU, vol. 2, pp. 54-57, 2013.

[2] V. Gasperz, Production Planning And Inventory Control Berdasarkan Pendekatan Sistem Terintegrasi MRP II dan JIT Mепијu Manufakturing 21. Jakarta: PT. Gramedia Pustaka Utama, 2005.

[3] J. E. Biegel, "Production Control: A Quantitative Approach," 1980.

[4] A. Siregar, "Penyusunan Jadwal Induk Produksi Pada PT. Hitachi Construction Machinery Indonesia," 2012.

[5] A. Z. Taqwa, "Analisis Kapasitas Produksi Pemecah Batu Stonr Crhusher Dengan Metode Capacity Requirement Planning (CRP)," $J$. Tek. Mesin, 2016.
[6] N. A. Nanih Suhartini and T. Mulyanto, "Implementasi Metode Cut And Fit Pada Penentuan Jadwal Induk Produksi Produk NSH," $J$. Ilm. Teknol. dan Rekayasa, vol. 25, 2020.

[7] Y. Nasution, A. H., dan Prasetyawan, Perencanaan \& Pengendalian Produksi, Pertama. Yogyakarta: Graha Ilmu, 2008.

[8] A. H. Nasution, Perencanaan dan Pengendalian Produksi, Pertama. Surabaya: Guna Widya, 2003.

[9] Fajrian Nur Adnan, "Optimasi Analisis Peramalan dengan Metode Regresi Weighted Moving Average," J. Inf. Syst., vol. 4, pp. 119-128, 2019.

[10] R. Supriyadi, "Penjadwalan Produksi LKS-Filler Pada Proses Ground Calcium Carbonate Menggunakan Metode MPS di Perusahaan Kertas," SINERGI, vol. 20, pp. 157-164, 2016. 